\title{
Erratum: The evolution of the brain, the human nature of cortical circuits, and intellectual creativity
}

\section{Javier DeFelipe ${ }^{1,2,3 *}$}

1 Instituto Cajal, Consejo Superior de Investigaciones Científicas, Madrid, Spain

${ }^{2}$ Laboratorio Cajal de Circuitos Corticales, Centro de Tecnología Biomédica, Universidad Politécnica de Madrid, Madrid, Spain

${ }^{3}$ Centro de Investigación Biomédica en Red sobre Enfermedades Neurodegenerativas, Madrid, Spain

*Correspondence:defelipe@cajal.csic.es

\section{Edited by:}

Jose L. Lanciego, University of Navarra, Spain

\section{A commentary on}

The evolution of the brain, the human nature of cortical circuits, and intellectual creativity

by DeFelipe, J. (2011). Front. Neuroanat. 5:29. doi: 10.3389/fnana.2011. 00029.

In the scale bar of Figure 10, there is an error. Instead of $10 \mathrm{~cm}$ it should be $20 \mathrm{~mm}$. In addition, in the text and in the legend of Figure 1, there is a reference to a sculpture of Don Quixote present at the Museum of Modern Art in Mexico, a picture taken by the author of the present article. However, the author intended to say that this sculpture reminds him of a typical Don Quixote.

\section{ACKNOWLEDGMENTS}

The author would like to thank Dr. Hervé Boutin (University of Manchester, UK) who pointed out the error in Figure 10.
Received: 24 April 2013; accepted: 24 April 2013; published online: 14 May 2013.

Citation: DeFelipe J (2013) Erratum: The evolution of the brain, the human nature of cortical circuits, and intellectual creativity. Front. Neuroanat. 7:10. doi: 10.3389/fnana.2013.00010

Copyright (c) 2013 DeFelipe. This is an openaccess article distributed under the terms of the Creative Commons Attribution License, which permits use, distribution and reproduction in other forums, provided the original authors and source are credited and subject to any copyright notices concerning any third-party graphics etc. 